\title{
SINGLE EVENT LATCHUP PROTECTION OF INTEGRATED CIRCUITS
}

\author{
P. Layton, D. Czajkowski, J. Marshall, H. Anthony, R. Boss \\ Space Electronics Inc. \\ 4031 Sorrento Valley Blvd., San Diego, California, USA \\ E-mail: playton@spaceelectronics.com; Tel: 619 452-4167; Fax: $619452-5499$
}

\begin{abstract}
This paper will report the test results from the development of the single event latchup protection circuitry (referred to as Space Electronics Inc.'s (SEI's) LPT'M technology) for several integrated circuits which are known to latchup at unacceptably low LET energies for space applications. Two devices were evaluated with LPTTM; the ADS7805 16 bit analog to digital converter and the GF10009 FPGA (Gatefield's 9000 gate flash programmable gate array).
\end{abstract}

\section{Introduction}

Many commercially available advanced technology CMOS and bipolar integrated circuits are latchup susceptible to single event effects caused by heavy ions or protons from cosmic rays or solar flares making them unsuitable for satellite applications. Remanufacturing the integrated circuits on an inherently SEL immune process has been an expensive and technically difficult option as is the alternate option of incorporating latchup protection and recovery circuitry in the spacecraft system electronics.

Space Electronics Inc. has developed several different circuits which provide protection and recovery of integrated circuits known to exhibit single event induced latchup. These circuits are integrated within the same package as the susceptible integrated circuit using MCM and modern packaging technology resulting in a device level solution providing minimum cost and minimum impact on the system.

The LPT ${ }^{\mathrm{TM}}$ circuit was designed to provide the following features to protect and recover the susceptible integrated circuit device:

a. Provide current limiting to the device.

b. Detect the increase in current during the SEL event above a preset threshold.

c. Force a shutdown of the protected device when the threshold is exceeded.

d. Hold the device in the shut down mode for a preset time interval.

e. Return the device supply voltage to its original operating level.
The LPT ${ }^{\mathrm{TM}}$ circuitry (patent pending) has the potential to be applied to a wide variety of susceptible devices. The specific implementation details such as current latchup protection threshold and supply off time are determined by characterization of the susceptible devices at a heavy ion facility. The LPT ${ }^{\mathrm{TM}}$ device impacts a satellite component system by converting a Single Event Latchup (SEL) into a recoverable event. Using mission specific or orbit radiation data, recoverable event rates can be calculated. The rate and number of these recoverable events is dependent on the fluence, energy, and species of radiation encountered by the device during the particular mission[1].

\section{LPT $^{\mathrm{TM}}$ Circuit}

The first device selected for latchup protection was the ADS7805. The preliminary circuit design and analysis was based on protecting the ADS7805 device, which is susceptible to SEL at low Linear Energy Transfer (LET) levels.

The ADS7805 integrated circuit draws current from an analog and digital supply pin. The LPT ${ }^{\mathrm{TM}}$ circuit must sense the current into the supply pins and when the latchup current threshold is exceeded, remove the supply voltage from the latched device. During the time that the supply voltage is removed from the device, the supply current draw will come exclusively from the LPT ${ }^{\text {TM }}$ circuit. After a set time interval required for the latchup to clear, the $\mathrm{LPT}^{\mathrm{TM}}$ circuit reapplies the supply voltage to the device and normal operation is restored.

Figure 2 shows the supply current with and without a protection circuit during a single event 
latchup. The LPT ${ }^{\mathrm{T}}$ circuit will have a latchup current threshold, I Ihreshold, an activation delay time, $t_{D}$, and recovery time, $t_{R E C}$, as shown in figure 2 (b). The LPT $^{\mathrm{T}}$ circuit is activated when the supply current exceeds the IThreshold value, the supply current is turned off (grounded) within time $t_{D}$ after $I_{\text {Threshold }}$ is reached. The device is off for time period $t_{R E C}$. This can be compared with the unprotected latchup supply current response shown in figure 2(a) where the normal operating current rises to the latchup current in response to a single event latchup.
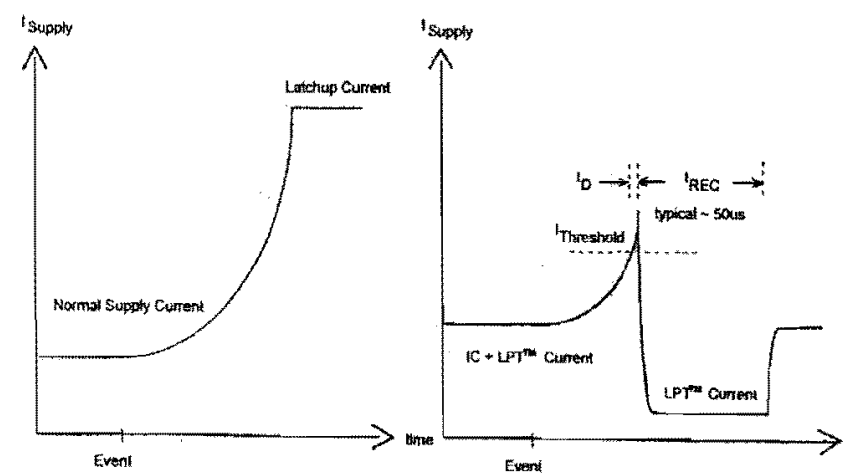

(a) unprotected

(b) protected circuit

Figure 2 Supply current waveforms

Two types of circuits were designed to protect and recover the ADS7805 from SEL. The primary components of the first circuit were a dual comparator and a logic level $P$ channel MOSFET. One comparator was used to detect when the latchup current threshold was exceeded and provide a limited duration control pulse when this occurred. The second comparator provided a status output to indicate to the system that latchup had been detected and power was removed from the ADS7805. The logic level $P$ channel MOSFET was used as a high side power switch to the ADS7805.

The second circuit used a specialized integrated circuit, the LTC1153 Auto Reset Electronic Circuit Breaker, available from Linear Technologies, Inc. [2] along with an $\mathrm{N}$ channel MOSFET. The LTC1153 provided latchup threshold detection, gate drive to the MOSFET including timed shutoff and status output to the system. The N-Channel MOSFET was operated as a high side power switch to the ADS7805.

In both LPT ${ }^{T M}$ circuits, the analog and digital supply inputs to the device were tied together through a low value current sense resistor and powered by a single supply input.

\section{Validation Test Results}

Both LPT ${ }^{\mathrm{TM}}$ circuit types were tested at the JPL Californium-252 source. Additionally, two different comparators devices were tested in the comparator circuit. One comparator exhibited higher speed with higher power, while the second comparator exhibited lower speed and significantly lower power.

The test circuit consisted of a breadboard of each LPT ${ }^{\mathrm{T}}$ circuit type, a de-lidded ADS7805 (the target of the radiation), and a 16 bit digital to analog converter circuit which provided a composite monitor of the ADS7805 parallel data output. The status signal was used to trigger a digital storage scope set to capture the supply current response and the composite monitor response. A full scale sinusoidal input signal was provided to the ADS7805 during all testing, and the composite output was continuously monitored by a waMM for loss of functional operation.

The test results from the JPL Californium-252 test are shown in table 1. The fragments from the Californium source exhibit an LET of $-42 \mathrm{MeV}$. $\mathrm{cm}^{2} / \mathrm{mg}$. Latchup protection and recovery was demonstrated for both circuit types over a range of input conditions, LPT TM delay and recovery times.

Note that under one test condition latchup recovery did not occur. This was due to the applied voltages and related current limiting on the digital input pins to the ADS7805. The first condition occurred with the CS, R/C, and BYTE signals tied to $+5 \mathrm{~V}$ (chip not selected) each through a 91 Ohm series resistor. When the resistors were increased to 511 Ohms, latchup recovery occurred. Values between 91 and 511 Ohms were not tested. This result showed that not only does the supply voltage have to be removed, but the inputs must be carefully considered to assure that backdriving the supply through input pins does not sustain the latchup.

Subsequent testing of the LPT ${ }^{\text {TM }}$ circuitry was performed at Texas A\&M University cyclotron. The primary concern of this testing was to determine if there were any latchup modes that were not exhibited with the limited LET characterization available from the Californium-252 source. Since the main concern of this test was the SEL response of the ADS7805, only 
the LTC1153 based circuit was tested. The results of this testing are summarized in table 2. The LPT ${ }^{\mathrm{rm}}$ circuit successfully recovered the ADS7805 from all SELs over an LET range of $14-80 \mathrm{MeV}-\mathrm{cm}^{2} / \mathrm{mg}$. Additionally, this testing bounded the SEL threshold of the ADS7805 between 9.9 and $14 \mathrm{MeV}-\mathrm{cm}^{2} / \mathrm{mg}$.

Figure 3 shows the LPT ${ }^{\text {TM }}$ operation in response to a single event latchup. Curve (a) shows the latchup current occurring and then the supply is cycled off then on. The current spike at turn-on is due to the high $\mathrm{dV} / \mathrm{dt}$ driving the decoupling capacitance on the ADS7805 supply pins. Figure $3 \mathrm{~b}$ shows the effect of the LPT protection and recovery on the ADS7805 output.
Figure 3

$7805 L P$ response to to Single Event Latchup so us LPT recovery time

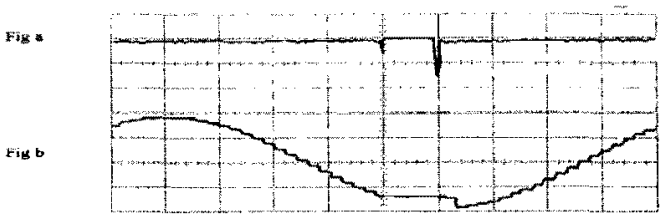

Figure (channel 1), is $I_{\text {MoN, }} 500 m$ VIDiv Figure o (channel 2) is Vour. 5 VIDiv all ohannels are $50 \mathrm{HeS} / \mathrm{Div}$

No destructive functional failures of any of the ADS7805 devices tested occurred during either radiation or flash testing.

Table 1: LPT $^{\text {TM }}$ Test Results at JPL Californium-252 Source

\begin{tabular}{|c|c|c|c|c|c|c|c|}
\hline $\begin{array}{c}\text { LPT } \\
\text { Circuit }\end{array}$ & Operation & $\begin{array}{c}\text { Series Rs } \\
(\text { Ohm })\end{array}$ & $\begin{array}{c}\text { tD } \\
(\mu \mathrm{s})\end{array}$ & $\begin{array}{c}\text { Latchup } \\
\text { Current }(\mathrm{mA})\end{array}$ & Recovery & $\begin{array}{c}\mathrm{T}_{\mathrm{REC}} \\
(\mathrm{ms})\end{array}$ & $\begin{array}{c}\text { LET } \\
\left(\mathrm{Mev}-\mathrm{cm}^{2} / \mathrm{mg}\right)\end{array}$ \\
\hline LTC1153 & Normal & 132 & 19 & $159-133$ & Yes & 2.5 & 42 \\
\hline $\begin{array}{c}\text { Slow } \\
\text { Comparator }\end{array}$ & Normal & 113 & 15 & $159-133$ & Yes & 2.5 & 42 \\
\hline $\begin{array}{c}\text { Slow } \\
\text { Comparator }\end{array}$ & $\begin{array}{c}\text { All Inputs } \\
\text { High }\end{array}$ & 91 & 15 & $159-133$ & No & & 42 \\
\hline $\begin{array}{c}\text { Slow } \\
\text { Comparator }\end{array}$ & $\begin{array}{c}\text { All Inputs } \\
\text { High }\end{array}$ & 1000 & 15 & $159-133$ & Yes & 2.5 & 42 \\
\hline $\begin{array}{c}\text { Fast } \\
\text { Comparator }\end{array}$ & $\begin{array}{c}\text { All Inputs } \\
\text { High }\end{array}$ & 511 & 1.5 & $159-133$ & Yes & 2.5 & 42 \\
\hline $\begin{array}{c}\text { Fast } \\
\text { Comparator }\end{array}$ & Normal & 511 & 1.5 & $159-133$ & Yes & 2.5 & 42 \\
\hline $\begin{array}{c}\text { Fast } \\
\text { Comparator }\end{array}$ & Normal & 511 & 1.5 & $159-133$ & Yes & $45 \mu \mathrm{s}$ & 42 \\
\hline
\end{tabular}

Table 2: LPT $^{\mathrm{TM}}$ Test Results at Texas A\&M University Cyclotron

\begin{tabular}{|c|c|c|c|c|c|c|c|}
\hline $\begin{array}{c}\text { LPT } \\
\text { Circuit }\end{array}$ & Operation & $\begin{array}{c}\text { Series } \\
\text { Rs } \\
(\text { Ohm })\end{array}$ & $\begin{array}{c}\text { tD } \\
(\mu \mathrm{s})\end{array}$ & $\begin{array}{c}\text { Latchup } \\
\text { Current } \\
(\mathrm{mA})\end{array}$ & Recovery & $\begin{array}{c}\mathrm{T}_{\text {REC }} \\
(\mathrm{ms})\end{array}$ & LET Mev-cm²/mg \\
\hline \hline LTC1153 & Normal & $1 \mathrm{k}$ & 19 & None & $\mathrm{n} / \mathrm{a}$ & 2.5 & 7 \\
\hline LTC1153 & Normal & $1 \mathrm{k}$ & 19 & None & $\mathrm{n} / \mathrm{a}$ & 2.5 & 9.9 \\
\hline LTC1153 & Normal & $1 \mathrm{k}$ & 19 & 267 & Yes & 2.5 & 14 \\
\hline LTC1153 & Normal & $1 \mathrm{k}$ & 19 & $146-267$ & Yes & 2.5 & 40 \\
\hline LTC1153 & Normal & $1 \mathrm{k}$ & 19 & $146-267$ & Yes & 2.5 & 56.6 \\
\hline LTC1153 & Normal & $1 \mathrm{k}$ & 19 & $146-267$ & Yes & 2.5 & 80 \\
\hline
\end{tabular}




\section{Implementation On Susceptable Devices}

Since the operating and latchup currents vary for different devices each device needs to be characterized for these parameters before an LPT ${ }^{\mathrm{TM}}$ can be designed for that particular device. The characterization of two such devices are described below.

\section{A. ADS7805 Testing}

Test results, as reported in JPL's radiation effects database [3] from a Brookhaven National Laboratory (BNL) heavy ion test conducted on 12/6/94, bounded SEL threshold for the ADS7805 below 38 $\mathrm{MeV}-\mathrm{cm}^{2} / \mathrm{mg}$. This threshold level created a high probability of latchup in a space environment, making this device unsuitable for space applications. The latchup current level from the BNL test was not reported. Typical operating current of the ADS7805 is specified as $16.3 \mathrm{~mA}$ for both the analog and digital $5 \mathrm{~V}$ supply. The maximum specified operating current [4] for the device is $20 \mathrm{~mA}$.

An interesting characteristic of the ADS7805 die was that latchup could be induced with a high intensity light source. We were able to trigger latchup by exposing de-lidded devices to the flash from a $35 \mathrm{~mm}$ camera flash bulb. Typical peak photoelectric currents were measured on the supply inputs at $\sim 650$ $\mathrm{mA}$ with a duration of $2 \mathrm{~ms}$. After the flash induced current dissipated, the device latchup current was measured to be $110 \mathrm{~mA}$. This latchup characteristic of the ADS7805 was used to electrically test and debug the LPT ${ }^{\mathrm{TM}}$ circuits during development and prior to radiation exposure.

Heavy ion characterization and validation of the ADS7805 with the LPT ${ }^{\mathrm{TM}}$ circuitry was performed using the Jet Propulsion Laboratories (JPL) Californium - 252 source at Pasadena $\mathrm{CA}$ and also using the Texas A\&M University Cyclotron facility. Latchup protection and recovery of the ADS7805 was demonstrated at both of these facilities. Peak latchup current was measured between 146 and $267 \mathrm{~mA}$ and device recovery was shown with supply off times of 45 $\mu \mathrm{sec}$ and $2.5 \mathrm{msec}$. Additional validation testing was performed by NASA Goddard Space Flight Center[5].

\section{B. Gatefield GF10009 FPGA Testing}

The Gatefield 9000 gate FPGA was tested at Texas A\&M's cyclotron and Berkeley National Laboratories 88 inch cyclotron. The device was tested to characterize the latchup current for incorporation in a latchup protected device.

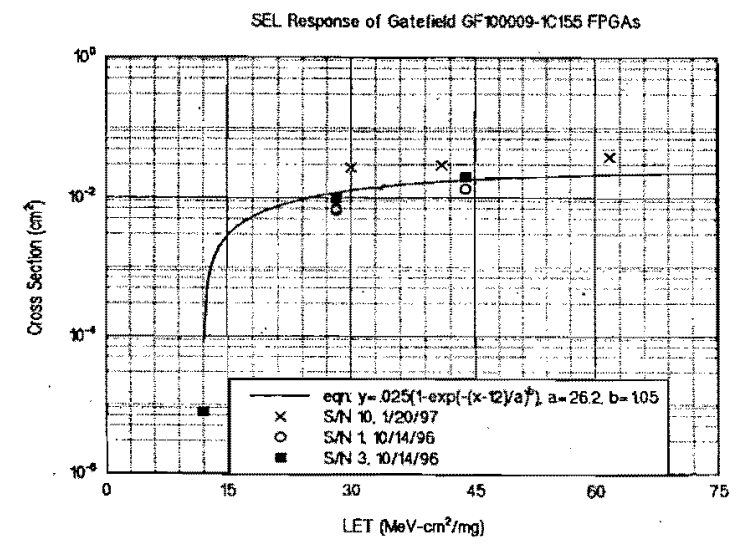

Figure 4. Cross Section vs. LET energy for the Gatefield 9000 gate FPGA.

The latchup cross section versus Linear Energy Transfer (LET) energy is plotted in figure 4. A wide variation in single event related current transients were observed. Typical latchup current was in the range of $300 \mathrm{~mA}$ to $800 \mathrm{~mA}$, however some heavy ion induced current increases were as high as $3.5 \mathrm{~A}$ and as low as $50 \mathrm{~mA}$. Test circuit functionality was maintained at the low current levels, however, full FPGA functionality was not monitored. Space Electronics Inc. is currently investigating the heavy ion response and the final design SEL detection threshold has not been set at this time.

\section{Productization}

The ADS7805 LPT ${ }^{\text {TM }}$ circuit has been developed into a multi-chip module referred to as the 7805RPLP. This device has the same footprint as the ADS7805 with some modification of the pin functions. The separate supplies are replaced by a single VS input. The ADS7805 common supply pin is made available for adding board level decoupling capacitance. The status output replaces the byte input which is internally grounded in the MCM. Care must be taken in the application not to backdrive the device when the status output is active. The latchup current threshold has been set typically at $80 \mathrm{~mA}$ with a recovery time of 50 microseconds. 
The 7805RPLP is packaged using SEI's RAD$\mathrm{PAK}^{\circledR}$ packaging technology. This packaging provides shielding of the internal devices from total dose radiation thereby enhancing their total dose hardness. Total dose enhancement is required for both the ADS7805 and the LPT'M components.

\section{Conclusions}

Important considerations for the design of latchup protected devices include:

1) Cycling power alone is not sufficient to return the device from a latched state, since the inputs may require current voltage limiting for the latchup protection circuit to work properly.

2) Each device needs to be validated at a heavy ion source to properly set the SEL current detection threshold and properly assess heavy ion response and recovery characteristics.

3) Microlatching can make protecting a circuit more difficult. If the microlatch current is close to the operating current of the device, the LPT ${ }^{\text {TM }}$ is not a solution for latchup. If the device is susceptible to microlatch, the microlatch current will need to be characterized for the device.

4) During Single Event Testing (SEE) devices are also susceptible to Total Ionizing Dose (TID), Devices with low TID levels may experience an increase in supply current from the TID. This can also pose a problem for actual space applications. The latchup detection threshold level for these devices must be set at levels consistent with the supply current increase caused by TID.

With proper characterization and design, sensitive devices can be protected at the package level from single event latchups.

Devices which previously were unsuitable for space applications based on their single event latchup threshold characteristics can now be used in a space environment using SEI's LPT ${ }^{\text {TM }}$ technology. This technology has been demonstrated for the ADS7805 16 bit analog to digital converter and a product designed for the space environment is available. The application of latchup protection to other devices such as the
Gatefield 9000 gate FPGA which exhibit complex SEE effects are being investigated by SEI.

This technology can be applied to a wide range of devices in order to provide new options for the use of commercially developed, leading edge technology components in a space environment.

\section{Acknowledgments}

RAD-PAK $^{(3)}$ is a registered trademark of Space Electronics Inc.

LPTTM is a trademark of Space Electronics Inc.

This work was partially supported by NASA contract No. NAS8-97186

\section{References}

1. Galloway and Johnson, "Catastrophic Single-Event Effects in the Natural Space Environment", IEEE Nuclear and Space Radiation Effects Conference Short Course, 1996.

2. LTC1153 Data Sheet, Linear Databook Vol. III, Linear Technology, 1994.

3. JPL test results for ADS7805 reported on world wide web.

4. ADS7805 Data Sheet, Linear Products Burr-Brown IC Data Book, 1996.

5. Moran and Label, " Single Event Effects Test Report on Heavy ion Testing at Brookhaven National Laboratories 5/13-16/97", NASA/GSFC web site http:/flick.gsfc.nasa.gov/radhome/papers/b051397b.htm.

\section{Additional References}

R. R. Troutman, "Latchup in CMOS Technology: The Problem and its Cure". Kluwar Academic Publishers, 1986.

H. Dussault, J.W. Howard Jr., R.C. Block, M.R. Pinto, W.J. Stapor, and A. R. Knudsen, "High Energy HeavyIon-Induced Single Event Transients in Epitaxial Structures," IEEE Trans. Nuc. Sci., vol. NS-41, pp.2018-2025, 1994.

E.G. Stassinopoulos, "Radiation Environments in Space," in Notes for the 1990 IEEE Nuclear and Space Radiation Effects Conference Short Course, 1990.

$11^{\text {th }}$ AIAA/USU Conference on Small Satellites 